\title{
5 Research Square

\section{Surgical Site Infection After Emergency Abdominal Surgery in China: A Multicenter Prospective Study}

Ze Li

The affiliated hospital of Qingdao University

Hui Li

The affiliated hospital of Qingdao University

Pin Lv

Qingdao mental health center区Qingdao University

Xingang Peng

The affiliated hospital of Qingdao University

Changliang Wu

The affiliated hospital of Qingdao University

Jianan Ren ( $\nabla$ Jiananr@gmail.com )

The affiliated hospital of Qingdao University

\section{Peige Wang}

The affiliated hospital of Qiangdao University https://orcid.org/0000-0002-4890-9964

\section{Research article}

Keywords: Surgical site infection, Emergency abdominal surgery, Risk-factors, Prevalence

Posted Date: June 9th, 2020

DOI: https://doi.org/10.21203/rs.3.rs-33387/v1

License: (c) (i) This work is licensed under a Creative Commons Attribution 4.0 International License.

Read Full License 


\section{Abstract}

Background There is still a lack of relevant studies on surgical site infection (SSI) after emergency abdominal surgery (EAS) in China. This study aims to understand the status of SSI after EAS in China and discuss its risk factors.

Materials and Methods All adult patients who underwent EAS in 47 hospitals in China from May 1 to 31, 2018, and from May 1 to June 7, 2019, were enrolled in this study. The basic information, perioperative data, and microbial culture results of infected incision were prospectively collected.The primary outcome measure was the incidence of SSI after EAS, and the secondary outcome variables were postoperative length of stay, ICU admission rate, ICU length of stay, 30-day postoperative mortality, and treatment costs. Univariate and multivariate logistic regression were used to analyze the risk factors.

Results A total of 953 patients (age $48.8 \pm 17.9$ years, male $51.9 \%$ ) with EAS were included in this study: 71 patients (7.5\%) developed SSI after surgery. The main pathogen of SSI was Escherichia coli (culture positive rate $29.6 \%)$. Patients with SSI had significantly longer overall hospital $(p<0.001)$ and ICU stays $(p<0.001)$, significantly higher ICU admissions $(p<0.001)$, and medical costs $(p<0.001)$ than patients without SSI.Multivariate logistic regression analysis showed that male $(P=0.010)$, high blood glucose level $(P<0.001)$, colorectal surgery $(P<0.001)$, intestinal obstruction $(P=0.045)$ and surgical duration $(P$ $=0.007)$ were risk factors for SSI, whereas laparoscopic surgery $(P<0.001=0.022)$ was a protective factor.

Conclusion This study found a high incidence of SSI after EAS in China. The occurrence of SSI prolongs the patient's hospital stay and increases the medical burden. The study also revealed predictors of SSI after EAS and provides a basis for the development of norms for the prevention of surgical site infection after emergency abdominal surgery.

\section{Introduction}

The WHO ststes in the surgical site infection prevention guideline [1]: Surgical site infection (SSI) is among the most common health-care-associated infections in developing countries. The occurrence of SSI causes great pain to patients, prolongs the length of hospital stay, and causes expensive treatment costs $[2,3]$.

Current studies have found that the incidence of SSI after abdominal surgery ranges from $1.2 \%$ to $5.2 \%$ [4-6]. The incidence of SSI is much higher in patients undergoing emergency abdominal surgery (EAS) than in elective surgery $[7,8]$. A cross-sectional study in the United States has shown that the incidence of incisional SSI in EAS patients is 6.7\%, however, the respective incidence and proportion of drug-resistant bacteria in China are higher $[9,10]$. In recent years, more patients undergo EAS with the rising number of emergency cases, patient management is more centralized, and the prevention of SSI has become more important [11]. However, there are limited studies on SSI after EAS in China. Therefore, it is important to obtain relevant data about SSI after EAS in China and provide a basis for its prevention. 
In this study, prospective clinical data was collected from EAS patients in 47 hospitals in China, and the associated risk factors were analyzed. This study aims to provide the necessary evidence for the prevention of SSI after EAS.

\section{Methods}

We conducted a multicenter, prospective, observational study. The demographic and perioperative characteristics were collected to further evaluate the rate, risk factors and microbiological profile of SSI after EAS in China.

All adult patients who underwent EAS in 47 tertiary hospitals in China from May 1, 2018, to May 31, 2018, and from May 1, 2019, to June 7, 2019, were included. The follow-up period was 30 days postoperatively ( patients with PP mesh had a 180 day postoperative follow-up). Patients who were participating in other clinical trials, pregnant, undergoing urologic, gynecologic, or transplant surgery were excluded.

Data related to SSI was collected according to established study protocols. Patient baseline variables included: Age, sex, body mass index (BMI), admission diagnosis, American Society of Anesthesiologists (ASA) physical status score, hypertension, diabetes mellitus, chronic hepatic dysfunction (hepatitis, cirrhosis, and/or abnormal liver enzymes levels), chronic renal dysfunction (renal failure and/or dialysis), chronic cardiac dysfunction (heart failure, myocardial infarction, previous percutaneous coronary intervention, and/or previous cardiac surgery), immune suppression status, smoking status (current smoker, former smoker, or nonsmoker), and preoperative concentrations of hemoglobin, albumin, and fasting blood glucose. Surgery-related variables included type of surgery based on surgical site (colorectal or non-colorectal), surgical wound class (clean-contaminated, contaminated, or dirty), methods of bowel preparation (mechanical bowel preparation [MBP] or oral antibiotic bowel preparation [OABP]), hand preparation (disinfectant or scrubbing), use of laparoscopy or robotic surgery, use of incisional protection devices (gauze, adhesive drapes, wound edge protector, or something else), grade of lead surgeon (based on their title), duration of surgery (from incision to suture), and the national nosocomial infections surveillance (NNIS) risk index. The NNIS risk index ranged from 0 to 3 per the assessment of three variables: ASA score, surgical wound class, and duration of surgery; the cutoff values for each variable were an ASA score of 3 , a contaminated surgical incision, and an operative time of $180 \mathrm{~min}$, with 1 point assigned when each variable exceeded its respective cutoff value [12]. Antibioticrelated variables included the use of preoperative and postoperative antibiotics.

The data collected consisted of three validation steps. First, each hospital identified patients according to the study protocol, collected basic data, and followed up the patients. Second, three independent investigators (ZL, HL, and PW) collated all data to assess its accuracy. Third, team members discussed the problem data and qualitatively assessed the collection process and data.

The primary outcome was the rate of SSI at 30 or 180 days; patients discharged from the hospital were followed up at the clinic or by telephone. The secondary outcome variables were postoperative hospital stay, ICU admission rate, ICU length of stay, treatment costs, and 30-day mortality. Surgical site infections 
were classified according to the Centers for Disease Control and Prevention (CDC) criteria; superficial incisional, deep incisional, and organ or space infections [13]. The diagnosed of SSI was by the presence of the following: (1) Local pain or tenderness, local swelling, redness, heat, or several of these symptoms, combined with deliberate or spontaneous incision dehiscence; (2) drainage at the incision or drainage tube; (3) imaging diagnosis of intra-incision abscess or abdominal and pelvic infections (including anastomotic leak). The fluid from the drain or puncture where SSI occured were cultured according to the standards of each hospital.

\section{Statistical Analysis}

Data analysis was performed using SPSS 22.0 software. All patients were divided into the SSI or the nonSSI groups. Categorical variables between the two groups were compared using the $\chi 2$ test, adjusted $\chi 2$ test, or Fisher's exact test. Continuous variables that were not normally distributed were expressed as medians (interquartile range) and compared using the Mann-Whitney $U$ test. Univariate and multivariate logistic regression analyses were used to identify predictors of SSI occurrence, in which continuous variables were substituted into the model by obtaining cut-off values through ROC curves. The signifificance level was set at the conventional level of $a=0.05$. $P$ values were two-sided, and $P<0.05$ was considered statistically significant.

\section{Result}

The patient flow chart is provided in Figure 1. There were 986 subjects initially recruited into the study; 16 were lost to follow-up, 13 were excluded due to incomplete data, and 5 due to problematic data. The 953 cases (534 males and 419 females) that met the inclusion criteria were followed up and analyzed. The mean age of the patients was $48.8 \pm 17.9$ years, ranging from 18 to 88 years. Of the total, 216 patients had one or more co-morbidities, with hypertension and diabetes mellitus being the most common comorbidities $(137,57)$ (Table 1$)$.

Postoperative SSI was identified in 71 (7.5\%) patients. The volume of patients with SSI, out of the total, in each participant hospital, is listed in Table S1. Among them, 23 patients $(32.4 \%)$ had superficial incision infection, 27 (38.0\%) had deep incision infection, and 21 (29.6\%) had organ-space infection. Secretion and pus cultures were positive in 42 patients (59.2\%); the pathogens were Escherichia coli in 21 patients (50.0\%), Klebsiella pneumoniae in 7 patients (16.7\%), Staphylococcus aureus in 6 patients (14.3\%), Enterococcus faecium in 4 patients (9.5\%), surface staphylococci in 2 patients (4.8\%), and Acinetobacter baumannii and Proteus mirabilis in 1 patient each (2.4\%). ICU admission and medical costs were significantly increased in the SSI group compared with the non-SSI group, and also, postoperative and ICU length of stay were significantly prolonged (Table 2). Four patients died within 30 days of surgery, but none was directly caused by SSI. The median duration from surgery to SSI was $5.2 \mathrm{~d}$.

Demographic characteristics: There was a higher incidence of SSI in male than in female patients $(p=$ $0.004)$, and in patients with diabetes mellitus than in those without it $(p=0.003)$. There was a statistically 
significant difference between the two groups in preoperative hemoglobin, albumin, and blood glucose concentrations $(p=0.012 ; 0.001 ; 0.000)$ (Table 1$)$.

Perioperative characteristics: Colorectal surgery patients had a higher rate of SSI than non-colorectal patients $(p<0.001)$; those with additional intestinal obstruction, had a higher rate of $S S I(p<0.001)$. The ASA score and NNIS risk index were significantly different between the two groups $(p<0.001 ; 0.001)$. The incidence of SSI was significantly lower in patients who underwent laparoscopic surgery than for those who underwent laparotomy. Adhesive drapes were the most commonly used wound protectors in EAS. Wound irrigation was significantly different between the groups $(p<0.001)$. The lead EAS surgeon was usually a senior surgeon. The duration of EAS was significantly longer in the SSI group than in the nonSSI group $(p<0.001)$ (Table 3$)$.

For antibiotic administration, a total of 707 patients received preoperative antibiotic. Third-generation cephalosporins were the most commonly used antibiotic type (32.8\%), followed by cephamycins and combination antibiotic. Antibiotic were used postoperatively in 872 patients, with the most patients receiving combination antibiotic (31.8\%), followed by the third-generation cephalosporins in 200 patients. Postoperative antibiotic use was significantly longer in the SSI group than in the non-SSI group $(p<$ 0.001) (Table 4).

Univariate logistic regression analysis risk factors results for SSI are shown in Figure 2. The factors significantly associated with the occurrence of SSI were age ( $>47.5$ years), male gender, preoperative albumin concentration ( $<11 \mathrm{~g} / \mathrm{dL}$ ), preoperative blood glucose concentration ( $>124 \mathrm{mg} / \mathrm{dL}$ ), colorectal surgery, intestinal obstruction, ASA score greater than 2, NNIS risk index greater than 0 , laparoscopic surgery, wound irrigation囚povidone iodine solution $\bigotimes$, and operation time (>122 min). Multivariate logistic regression analysis confirmed that males, blood glucose concentration (>124 mg/dL), colorectal surgery, intestinal obstruction, and surgical duration (> $122 \mathrm{~min}$ ) were risk factors for SSI, while laparoscopic surgery was a protective factor.

\section{Discussion}

his study found that the incidence of postoperative SSI in EAS patients was 7.5\%, with Escherichia coli infection being the most common, which is comparable to that reported worldwide $[9,14,15]$. The occurrence of SSI significantly prolonged the hospital stay of patients and increased medical costs. The incidence of SSI can be reduced by laparoscopic surgery and shorter operation time, whereas high blood glucose levels, intestinal obstruction, and colorectal surgery increase the risk.

It has been shown that older people are more likely to develop SSI [16] ; in this study, age was not a predictor as observed using multivariate logistic regression analysis. Male patients had a significantly higher risk of SSI after EAS than females (OR 2.204, 95\% Cl $1.178-8.985, \mathrm{P}=0.010$ ); while this is partly debated, multiple studies have found significantly higher rates of SSI in male patients than in females $[17,18]$. This may be related to male bushy hair; shaving increases the risk of skin trauma. Guidelines for 
SSI prevention issued by the Surgical Infection Society strongly discourage the use of razors for hair removal and propose the use of clippers if necessary.

In our study, high blood glucose level ( $>124 \mathrm{mg} / \mathrm{dL}$ ) was found to be a risk factor for SSI after EAS (OR $3.328,95 \% \mathrm{Cl} 1.888-5.867, \mathrm{P}<0.001)$. Previous studies have shown that diabetes mellitus and preoperative hypergycemia are SSI risk factors [19]. Hyperglycemia can affect the function of white blood cells, which in turn reduces the body's defense. The EAS patients tend to be in an acute preoperative stress state, and the associated hyperglycemic levels can better predict SSI than diabetes. Decreased serum albumin is usually an indicator of malnutrition or combined chronic wasting disease. In the present study, low serum albumin levels did not significantly affect the occurrence of SSI after adjustment for other variables, which requires further investigation.

The incidence of postoperative SSI is generally higher in patients undergoing colorectal than other gastrointestinal surgeries [20]. Our data shows that patients undergoing emergency colorectal surgery are at 7.017 times $(95 \% \mathrm{Cl} 3.577-13.805, \mathrm{P}<0.001)$ higher risk of SSI than patients undergoing other emergency gastrointestinal surgeries. There is a high colorectal bacterial load, including a variety of gram-negative and anaerobic bacteria. Necessary bowel preparation is difficult to achieve for emergency surgery and intestinal contents are easily spilled, contaminating the surgical area. This explains the high risk of SSI in emergency colorectal surgery patients.

Our study found that intestinal obstruction was a risk factor for SSI (OR 1.973, 95\% Cl 1.014-3.838, P = 0.045). The intestinal barrier function is impaired due to fasting and dilatation of the bowel lumen regardless of whether the bowel is removed, and bacteria are easily translocated outside the bowel lumen, increasing the risk of SSI. In our study, gastrointestinal perforation was not an independent risk factor for SSI. Gastrointestinal perforation usually occurs in the upper gastrointestinal tract, which has a relatively less bacterial load. At the same time, more attention is often paid to SSI prevention during the treatment of patients with gastrointestinal perforation, including adequate irrigation of the surgical site and postsurgical application of high-grade antibiotics. There is need to pay attention to the prevention of SSI in patients with intestinal obstruction regardless of whether bowel resection is performed or not.

Our study also evaluated the relationship of ASA score, NNIS risk index, and wound irrigation with SSI. None of these were independent risk factors for SSI in EAS patients after adjustment for logistic regression analysis. The NNIS risk index included ASA score, duration of surgery, and surgical wound grade. The majority of patients had an ASA score of 1 or 2 , and surgical wounds were classified as cleancontaminated. The incidence of SSI was higher in patients whose incisions were irrigated with saline and povidone-iodine solution. This may be due to more contaminated incisions being irrigated than clean incisions during surgery, therefore spreading the infective microbes. The World Society for Emergency Surgery (WSES) states in the Intraoperative Surgical Site Infection Control and Prevention that there is insufficient data to support the role of irrigation of the incision with saline or polyvidone before closure in preventing SSI [21]. 
Previous studies have shown that laparoscopic surgery can significantly reduce the incidence of SSI compared to open surgery $[20,22]$. This study supports this view. Laparoscopic surgery uses a small incision, greatly reducing the chances of exposure with little damage to the surrounding tissues, which reduces the risk of SSI. However, laparoscopic surgery has some limitations, especially for emergency cases. Laparoscopy requires certain equipment base, operating space, and experienced surgeons. In the 2016 WSES consensus on the management of intra-abdominal infections, laparoscopic surgery was determined to be safe and preferred for procedures such as appendectomy, repair of perforated peptic ulcer, and cholecystectomy when contraindications are excluded [23]. However, if peritonitis episodes were $>24 \mathrm{~h}$, laparotomy was recommended.

The duration of surgery is a risk factor for SSI [24, 25]. This study found that EAS patients who had longer surgery were more likely to have an SSI. Longer surgery not only aggravates the destruction of the microenvironment in the surgical area, but also greatly increases the chances of bacterial colonization due to the increased exposure time of the surgical incision to the air. Precautions against SSI can be appropriately instituted for operation time greater than $122 \mathrm{~min}$.

We also analyzed patients' perioperative antibiotic use. The Infectious Diseases Society of America recommended administering prophylactic antibiotics only when indicated [26]. However, EAS patients are mostly treated for the primary disease in the emergency department before surgery; in our study 707 (74.2\%) patients had received different classes of antibiotics, preoperatively. This shows that there is lack of perioperative antibiotic standards for use in emergency surgery in China. Further randomized controlled trials are needed to determine the type and timing of antibiotic therapy. The WHO and the Infectious Diseases Society of America recommend that the administration of antibiotics should not be prolonged after surgery $[1,26]$. Interestingly, we found that the high incidence of SSI was associated with prolonged antibiotic administration; EAS patients who were on prophylactic antibiotics, are usually continued on antibiotics post surgically. The study shows that prolonged prophylactic antibiotics use is not beneficial in reducing the incidence of SSI, but leads to intestinal flora disturbances, drug-resistant bacteria, and increased medical burden $[27,28]$.

\section{Limitations Of The Study}

This study has several limitations. The study period is short and only includes patients who underwent EAS from May 1 to May 31, 2018, and May 1, June 7, 2019, which may have some bias. The study included different types of patients, which may be a confounding factor. Also, the results of bacterial culture of samples may be biased due to different standards and technical levels of culturing in each hospital. The multicenter study will be refined in the coming years.

\section{Conclusions}

This study found a high incidence of SSI after EAS in China. The occurrence of SSI prolongs the patient's hospital stay and increases the medical burden. We suggest that SSI monitoring should be performed 
according to the patient's gender, preoperative blood glucose level, disease, type and duration of surgery. Our study provides a basis for the development of norms for the prevention of SSI after EAS.

\section{Abbreviations}

ASA:

American Society of Anesthesiologists

CDC:

Center for Disease Control and Prevention

EAS:

Center for Disease Control and Prevention

ICU:

Intensive Care Unit

NNIS:

National Healthcare Safety Network

PP mesh:

Polypropyleneps mesh

SPSS:

Statistical Package for Social Sciences

SSI:

Surgical site infections

WHO:

World Health Organization

WSES:

World Society for Emergency Surgery

\section{Declarations}




\section{Ethics approval and consent to participate}

The institutional ethics committees of all participating hospitals approved this study. Written informed consent was obtained from all study participants

\section{Consent for publication}

Not applicable

\section{Availability of data and materials}

The datasets generated and analyzed during the current study are not publicly available. Because they are archived in the clinical databases of all participating hospital and the Affiliated Hospital of Qingdao University, they are only used for scientific purposes. Datasets are available from the corresponding author upon request.

\section{Competing interests}

The authors declared no potential Competing interest with respect to the research, authorship, and/or publication of this article.

\section{Funding}

This study is funded by Taishan Scholar Foundation of Shandong Province (Grant no. 2018092901) and Innovation Project of Military Medicine (16CXZ007).

\section{Authors' contributions}

Peige Wang, Jianan Ren and Ze Li designed and originated the study; Ze Li,Hui Li and Changliang Wu were responsible for the collection of clinical data; Ze Li and Pin Lv analyzed the data; Ze Li, Hui Li and Xingang Peng wrote the paper. All authors read and approved the final manuscript.

\section{Acknowledgements}

We would like to thank Suming Luo (people's hospital of Xinjiang uygur autonomous region), Jie Zhao (Shangqiu first people's hospital), Qingjun Zeng (Yueyang first people's hospital), Xinjian Xu (first affiliated hospital of Xinjiang medical university), Yanhong Weng (Shoukang hospital), Hao Zhang (Dongguan kanghua hospital), Qingzhong Yuan (Shengli oilfield central hospital of Shandong province), Shichen Wang (the 901th hospital of the PLA), Nansheng Liao (the first people's hospital of Taizhou city), Wei Mai (the people's hospital of Guangxi zhuang autonomous region), Shuhua Li (Zigong first people's hospital), Hui Cao (general hospital of dongfang hospital group), Feng Wang(Tsinghua university affiliated Beijing Tsinghua chang gung hospital), Gang Han (the second hospital of Jilin university), Hongbin Liu ( Lanzhou general hospital of Lanzhou military), Jianwen Zhang (Chenzhou first people's hospital), Zhiming Wu (Shaoxing central hospital), Hua Yang (Zigong fourth people's hospital), 
Hao Wang (people's hospital of Dongying city), Weidog Jin (central war zone hospital of PLA), Jun Zhang (FAW general hospital of Jilin province), Wenbiao Xie (the second hospital, university of south China), Dongming Zhang (Baotou central hospital), Weishun Liao (Langxi county traditional chinese medicine hospital), Haiyang Zhang (Nanyang city center hospital), Jiancheng Tu (Zhangjiagang first people's hospital), Zejian Lv (Guangdong provincial people's hospital), Wanwen Zhao (Xishan people's hospital of Wuxi city), Zeqiang Ren (the affiliated hospital of Xuzhou medical university), Peng Cui (Heji hospital affiliated to Changzhi medical college), Yong Peng (Nanchong central hospital), Yongshun Gao (the first affiliated hospital of Zhengzhou university), Daorong Wang (northern Jiangsu people's hospital), Xin Chen (the second affiliated hospital of Dalian medical university), Lie Wang (the 900th hospital of the PLA), Tao Yang (Tianjin first central hospital), Hongliang Yao (the second Xiangya hospital of central south university), Wei Zhou (Sir Run Run Shaw Hospital of Zhejiang University School of Medicine), Weihua Fu (general hospital of Tianjinmedical university), Jianjun Wu (Liyang people's hospital), Jiang Li (the first affiliated hospital of Kunming medical university), Guangyi Li (Hunan people's hospital), Baoqing Jia (Chinese PLA general hospital), Jiankun Hu (West China Hospital) , Zeqiang Ren (the affiliated hospital of Xuzhou medical university) for collecting the data of EAS patients.

\section{References}

1. Allegranzi B, Bischoff P, de Jonge S, Kubilay NZ, Zayed B, Gomes SM et al. New WHO recommendations on preoperative measures for surgical site infection prevention: an evidence-based global perspective. Lancet Infect Dis. 2016; 16(12):e276-e287.

2. Bluebelle, Study, Group. Validation of the Bluebelle Wound Healing Questionnaire for assessment of surgical-site infection in closed primary wounds after hospital discharge. Br J Surg. 2019; 106(3):226-235

3. Jenks PJ, Laurent M, McQuarry S, Watkins R. Clinical and economic burden of surgical site infection (SSI) and predicted financial consequences of elimination of SSI from an English hospital. JHhosp Infect. 2014; 86(1):24-33.

4. Allegranzi B, Bagheri NS, Combescure C, Graafmans W, Attar H, Donaldson L et al. Burden of endemic health-care-associated infection in developing countries: systematic review and metaanalysis. Lancet; 2011; 377(9761):228-241.

5. World Health Organization. Report on the endemic burden of healthcare $\otimes$ associated infection worldwide $₫ M \unrhd$. Geneva $₫$ WHO Press $₫ 2011 \llbracket 6-7$.

6. Wang Z, Chen J, Wang P, Jie Z, Jin W, Wang G et al. Surgical Site Infection After Gastrointestinal Surgery in China: A Multicenter Prospective Study. J Surg Res. 2019; 240:206-218.

7. El-Kholy AA, Elanany MG, Sherif MM, Gad MA. High Prevalence of VIM, KPC, and NDM Expression among Surgical Site Infection Pathogens in Patients Having Emergency Surgery. Surg Infect (Larchmt). 2018; 19(6):629-633.

8. Wang Z, Chen J, Ren J, Wang P, Jie Z, Jin W et al. [Surgical site infection following abdominal surgery in China: a multicenter cross-sectional study]. Zhonghua Wei Chang Wai Ke Za Zhi. 2018; 
21(12):1366-1373.

9. Hall C, Regner J, Abernathy S, Isbell C, Isbell T, Kurek S et al. Surgical Site Infection after Primary Closure of High-Risk Surgical Wounds in Emergency General Surgery Laparotomy and Closed Negative-Pressure Wound Therapy. J Am Coll Surg. 2019; 228(4):393-397.

10. Surgical site infection after gastrointestinal surgery in high-income, middle-income, and low-income countries: a prospective, international, multicentre cohort study. Lancet Infect Dis. 2018; 18(5):516525.

11. New WHO recommendations on preoperative measures for surgical site infection prevention: an evidence-based global perspectiveTabiri S, Yenli E, Kyere M, Anyomih TTK. Surgical Site Infections in Emergency Abdominal Surgery at Tamale Teaching Hospital, Ghana. Journal of clinical medicine. 2018; 42(4):916-922.

12. Bustamante-Munguira J, Herrera-Gómez F, Ruiz-Álvarez M, Figuerola-Tejerina A, Hernández-Aceituno A. A New Surgical Site Infection Risk Score: Infection Risk Index in Cardiac Surgery. Maedica (Buchar). 2019; 8(4).

13. Hunger R, Mantke A, Herrmann C, Mantke R. Triclosan-coated sutures in colorectal surgery : Assessment and meta-analysis of the recommendations of the WHO guideline. Der Chirurg; Zeitschrift fur alle Gebiete der operativen Medizen. 2019; 90(1):37-46.

14. El-Kholy AA, Elanany MG, Sherif MM, Gad MA. High Prevalence of VIM, KPC, and NDM Expression among Surgical Site Infection Pathogens in Patients Having Emergency Surgery. Surgical infections. Surg Infect (Larchmt). 2018; 19(6):629-633.

15. Hajibandeh S, Hajibandeh S, Bill V, Satyadas T. Meta-analysis of Enhanced Recovery After Surgery (ERAS) Protocols in Emergency Abdominal Surgery. World J Surg. 2020.

16. Ling ML, Apisarnthanarak A, Abbas A, Morikane K, Lee KY, Warrier A et al. APSIC guidelines for the prevention of surgical site infections. Antimicrob Resist Infect Control. 2019; 8:174.

17. Tabiri S, Yenli E, Kyere M, Anyomih TTK. Surgical Site Infections in Emergency Abdominal Surgery at Tamale Teaching Hospital, Ghana. World J Surg 2018; 42(4):916-922.

18. Aghdassi SJS, Schröder C, Gastmeier P. Gender-related risk factors for surgical site infections. Results from 10 years of surveillance in Germany. Antimicrob Resist Infect Control. 2019; 8:95.

19. de Vries FE, Gans SL, Solomkin JS, Allegranzi B, Egger M, Dellinger EP et al. Meta-analysis of lower perioperative blood glucose target levels for reduction of surgical-site infection. Br J Surg. 2017; 104(2):e95-e105.

20. Du M, Liu B, Li M, Cao J, Liu D, Wang Z et al. Multicenter surveillance study of surgical site infection and its risk factors in radical resection of colon or rectal carcinoma. BMC Infect Dis. 2019; 19(1):411.

21. De Simone B, Sartelli M, Coccolini F, Ball CG, Brambillasca P, Chiarugi M et al. Intraoperative surgical site infection control and prevention: a position paper and future addendum to WSES intraabdominal infections guidelines. World J Emerg Surg. 2020; 15(1):10.

22. Jaschinski T, Mosch CG, Eikermann M, Neugebauer EA, Sauerland S. Laparoscopic versus open surgery for suspected appendicitis. Cochrane Database Syst Rev. 2018; 11(11):Cd001546. 
23. Sartelli M, Chichom-Mefire A, Labricciosa FM, Hardcastle T, Abu-Zidan FM, Adesunkanmi AK et al. The management of intra-abdominal infections from a global perspective: 2017 WSES guidelines for management of intra-abdominal infections. World J Emerg Surg. 2017; 12:29.

24. Hamza WS, Salama MF, Morsi SS, Abdo NM, Al-Fadhli MA. Benchmarking for surgical site infections among gastrointestinal surgeries and related risk factors: multicenter study in Kuwait. Infect Drug Resist. 2018; 11:1373-1381.

25. Amri R, Dinaux AM, Kunitake H, Bordeianou LG, Berger DL. Risk Stratification for Surgical Site Infections in Colon Cancer. JAMA surg. 2017; 152(7):686-690.

26. Ban KA, Minei JP, Laronga C, Harbrecht BG, Jensen EH, Fry DE et al. American College of Surgeons and Surgical Infection Society: Surgical Site Infection Guidelines, 2016 Update. J Am Coll Surg. 2017; 224(1):59-74.

27. Sartelli M, Kluger Y, Ansaloni L, Coccolini F, Baiocchi GL, Hardcastle TC et al. Knowledge, awareness, and attitude towards infection prevention and management among surgeons: identifying the surgeon champion. World J Emerg Surg. 2018; 13:37.

28. Branch-Elliman W, O'Brien W, Strymish J, Itani K, Wyatt C, Gupta K. Association of Duration and Type of Surgical Prophylaxis With Antimicrobial-Associated Adverse Events. JAMA surg. 2019; 154(7):590598.

\section{Tables}


Table1 Demographics of included patients

\begin{tabular}{|c|c|c|c|c|}
\hline es & $\begin{array}{c}\text { SSI group } \\
(\mathrm{n}=71)\end{array}$ & $\begin{array}{c}\text { Non-SSI group } \\
(\mathrm{n}=882)\end{array}$ & Statistic & $\begin{array}{c}P \\
\text { value } \\
\end{array}$ \\
\hline \multirow{3}{*}{$\begin{array}{l}\text { ars\median (IQR) } \\
(\%)\end{array}$} & $56 \square 48-70 \square$ & $47 \square 33-63 \square$ & $\bar{U}=39918$ & $\overline{00.001}$ \\
\hline & & & $\chi^{2}=8.173$ & 0.004 \\
\hline & 51ロ9.6॰ & 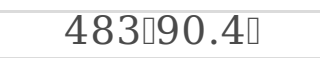 & & \\
\hline e & $20 \square 4.8 \square$ & $399 \square 95.2 \square$ & & \\
\hline$r / m^{2} \square$ median (IQR) & $23.0 \square 22.0-26.0 \square$ & $\begin{array}{l}23.0 \square 22.0- \\
24.4)\end{array}$ & $\mathrm{U}=20738.5$ & 0.695 \\
\hline Jidity (\%) & & & & \\
\hline tes mellitus & $10 \square 17.5 \square$ & 47ロ82.5ロ & $\chi^{2}=8.958$ & 0.003 \\
\hline rtension & $14 \square 10.2 \square$ & $123 \square 89.8 \square$ & $\chi^{2}=1.779$ & 0.182 \\
\hline aic liver disease & $1(5.9)$ & $16(94.1)$ & $\chi^{2}=0.021$ & 0.885 \\
\hline aic kidney disease & $3(13.6)$ & $19(86.4)$ & $\chi^{2}=0.500$ & 0.479 \\
\hline aic heart disease & $3(9.4)$ & $29(90.6)$ & $\chi^{2}=0.006$ & 0.937 \\
\hline rculosis & $1(12.5)$ & $7(87.5)$ & & 0.463 \\
\hline id use & 0 & $6(100)$ & & 1.000 \\
\hline inosuppressive medication & 0 & $2(100)$ & & 1.000 \\
\hline g history (\%) & & & $\chi^{2}=3.036$ & 0.219 \\
\hline & $58 \square 7.2 \square$ & 747๑92.8凸 & & \\
\hline Pr & 3ロ18.8॰ & $13(81.2)$ & & \\
\hline nt & $10 \square 7.6 \square$ & $122 \square 92.4 \square$ & & \\
\hline lobin, g/dL, median (IQR) & $12.5 \square 9.8-14.5 \square$ & $\begin{array}{l}13.1012 .0- \\
14.4 \square\end{array}$ & $\mathrm{U}=25430.5$ & 0.012 \\
\hline n, g/dL, median (IQR) & $3.6 \square 3.0-4.3 \square$ & $4.0(3.6-4.5)$ & $\mathrm{U}=22932.5$ & 0.001 \\
\hline flucose, $\mathrm{mg} / \mathrm{dL}$, median & 144ロ106-199ロ & 108(93-128) & $\mathrm{U}=43743$ & [0.001 \\
\hline
\end{tabular}

\section{Outcomes of included patients}

\begin{tabular}{|c|c|c|c|c|}
\hline es & $\begin{array}{l}\text { SSI group } \\
(\mathrm{n}=71)\end{array}$ & $\begin{array}{c}\text { Non-SSI } \\
\text { group } \\
(\mathrm{n}=882) \\
\end{array}$ & Statistic & $\begin{array}{c}\mathrm{P} \\
\text { value }\end{array}$ \\
\hline $\begin{array}{l}\text { erative delivery of icu, n(\%) } \\
\text { of ICU stay, day, median (IQR) }\end{array}$ & $\begin{array}{l}36 \square 18.2 \square \\
0(0-2)\end{array}$ & $\begin{array}{l}195 \square 91.8 \square \\
0(0-0)\end{array}$ & $\begin{aligned} \chi^{2} & =29.259 \\
\mathrm{U} & =41004\end{aligned}$ & $\begin{array}{l}\square 0.001 \\
00.001\end{array}$ \\
\hline $\begin{array}{l}\text { of postoperative stay, day, } \\
\text { (IQR) }\end{array}$ & 13ロ8-19๑ & 6ロ4-9ロ & $\mathrm{U}=49486$ & $\square 0.001$ \\
\hline $\begin{array}{l}\text { l cost, thousand dollar, median } \\
\text { ortality, } \mathrm{n}(\%)\end{array}$ & $\begin{array}{l}6.9 \square 3.7-9.7 \square \\
2 \square 50 \% \square\end{array}$ & $\begin{array}{l}2.3(1.7-3.8) \\
2 \square 50 \% \square\end{array}$ & $\mathrm{U}=51318$ & $\begin{array}{r}\square 0.001 \\
0.030\end{array}$ \\
\hline
\end{tabular}


Table3 Perioperative characteristics of included patients

\begin{tabular}{|c|c|c|c|c|}
\hline es & $\begin{array}{c}\text { SSI group } \\
(\mathrm{n}=71)\end{array}$ & $\begin{array}{c}\text { Non-SSI } \\
\text { group }(n=882) \\
\end{array}$ & Statistic & $\begin{array}{c}\mathrm{P} \\
\text { value } \\
\end{array}$ \\
\hline surgery(\%) & & & $\chi^{2}=72.133$ & 00.001 \\
\hline zctal surgery & 22৫34.3■ & 42ロ65.7ロ & & \\
\hline jlorectal surgery & $49 \square 5.5 \square$ & 840ロ94.5ロ & & \\
\hline preparation (\%) & & & & 0.528 \\
\hline & $62(7.4)$ & 778(92.6) & & \\
\hline only & $4 \square 12.9 \square$ & $27(87.1)$ & & \\
\hline only & $5 \square 6.3 \square$ & $75(93.7)$ & & \\
\hline OABP & 0 & $2 \square 100.0 \square$ & & \\
\hline ial obstruction(\%) & & & $\chi^{2}=29.526$ & $\square 0.001$ \\
\hline & $\begin{array}{c}20 \square 21.5 \square \\
51 \square 5.9 \square\end{array}$ & $\begin{array}{c}73 \square 78.5 \square \\
809 \square 94.1 \square\end{array}$ & & \\
\hline ntestinal perforation(\%) & & & $\chi^{2}=0.031$ & 0.861 \\
\hline & $\begin{array}{c}6 \square 7.0 \square \\
65 \square 7.5 \square\end{array}$ & $\begin{array}{c}80 \square 93.0 \square \\
802 \square 92.5 \square\end{array}$ & & \\
\hline ore(\%) & & & $\chi^{2}=31.630$ & 00.001 \\
\hline & $15(4.2)$ & $340(95.8)$ & & \\
\hline & $28(6.5)$ & $406(93.5)$ & & \\
\hline & $20(15.2)$ & $112(84.8)$ & & \\
\hline & $8 \square 25.0 \square$ & $24(75.0)$ & & \\
\hline isk index & & & $\chi^{2}=91.767$ & $\square 0.001$ \\
\hline & 17๑3.0॰ & $551 \square 97.0 \square$ & & \\
\hline & 27ロ9.7ロ & $252 \square 90.3 \square$ & & \\
\hline & $\begin{array}{c}19 \square 20.7 \square \\
8 \square 57.10\end{array}$ & $\begin{array}{c}73 \square 79.3 \square \\
6 \sqcap 42.9 \square\end{array}$ & & \\
\hline ch & & & $\chi^{2}=53.600$ & 00.001 \\
\hline & $61(14.4)$ & $362(85.6)$ & & \\
\hline oscopic & $10(1.9)$ & $520(98.1)$ & & \\
\hline al wound class(\%) & & & $\chi^{2}=0.766$ & 0.381 \\
\hline 1-contaminated & $4807.0 \square$ & $639(93.0)$ & & \\
\hline tminated or dirty & $23(8.6)$ & $243(91.4)$ & & \\
\hline lal protection (\%) & & & $\chi^{2}=23.051$ & {$[0.001$} \\
\hline & $29(5.1)$ & $537(94.9)$ & & \\
\hline $\mathrm{e}$ & $14(9.4)$ & $135(90.6)$ & & \\
\hline sive drapes & $12(7.6)$ & $145(92.4)$ & & \\
\hline id edge protector & $16(19.8)$ & $65(80.2)$ & & \\
\hline irrigation(\%) & & & $\chi^{2}=23.442$ & $\square 0.001$ \\
\hline & $12(2.9)$ & $406(97.1)$ & & \\
\hline 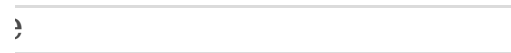 & $35(10.3)$ & $306(89.7)$ & & \\
\hline one iodine solution & $24(12.4)$ & $170(87.6)$ & & \\
\hline of lead surgeon (\%) & & & $\chi^{2}=12.356$ & 0.002 \\
\hline 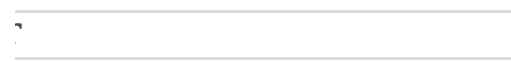 & 0 & $71(100.0)$ & & \\
\hline $\mathrm{e}$ & $22(5.6)$ & $371(94.4)$ & & \\
\hline $\mathrm{r}$ & $49(10.0)$ & $440(90.0)$ & & \\
\hline il duration, min, median & $\begin{array}{c}130.0(83.0- \\
205.0)\end{array}$ & $75.0(53.0-114.3)$ & $\mathrm{U}=45556.5$ & $\square 0.001$ \\
\hline
\end{tabular}


Antibiotics use

\begin{tabular}{|c|c|c|c|c|}
\hline Variables & $\begin{array}{c}\text { SSI group } \\
(\mathrm{n}=71)\end{array}$ & $\begin{array}{c}\text { Non-SSI } \\
\text { group } \\
(\mathrm{n}=882)\end{array}$ & Statistic & P value \\
\hline \multirow{2}{*}{$\begin{array}{l}\text { rative prophylactic } \\
\text { tic(\%) }\end{array}$} & & & & 0.005 \\
\hline & 14₫5.7ロ & 232凸94.3■ & & \\
\hline phalosporin & $14 \square 9.6 \square$ & $70 \square 90.4 \square$ & & \\
\hline phalosporin & $21 \square 4.8 \square$ & $211 \square 95.2 \square$ & & \\
\hline mycin & $6 \square 2.4 \square$ & $137 \square 4.0)$ & & \\
\hline phem & $1 \square 93.0 \square$ & $23 \llbracket 4.0)$ & & \\
\hline $\operatorname{llin}$ & $2 \square 93.0 \square$ & $70 \square 4.0)$ & & \\
\hline glycoside & $0 \square 17.5 \square$ & $3 \square 82.5 \square$ & & \\
\hline lones & $106.8 \square$ & $22 \llbracket 93.2 \square$ & & \\
\hline \multirow{2}{*}{ nidazole } & $\begin{array}{l}5 \square 93.0 \square \\
20102 \pi\end{array}$ & $\begin{array}{l}14 \square 93.2 \square \\
13 \pi 898 \pi\end{array}$ & & \\
\hline & $0 \square 7.0 \square$ & $4 \square 93.0 \square$ & & \\
\hline ned antibiotic & 5๑93.0ロ & 83๘93.0॰ & & \\
\hline \multirow[t]{2}{*}{ rative antibiotic(\%) } & & & & 0.002 \\
\hline & $2 \square 7.6 \square$ & $79 \llbracket 92.4 \square$ & & \\
\hline phalosporin & $6 \square 47.0 \square$ & $81 \square 24.0 \square$ & & \\
\hline phalosporin & $17 \square 12.2 \square$ & $183(8.6)$ & & \\
\hline mycin & $9 \square 5.2 \square$ & 123(1.9) & & \\
\hline phem & $2 \square 92.4 \square$ & $16 \square 92.4 \square$ & & \\
\hline $\operatorname{llin}$ & $5 \square 34.3 \square$ & $68 \square 92.4 \square$ & & \\
\hline iglycoside & $105.5 \square$ & $2 \square 65.7 \square$ & & \\
\hline lones & $1 \square 92.4 \square$ & $23 \llbracket 94.5 \square$ & & \\
\hline penem & $9(7.4)$ & $30 \square 92.4 \square$ & & \\
\hline \multirow[t]{2}{*}{ nidazole } & $1012.9 \square$ & $0(87.1)$ & & \\
\hline & $3 \square 6.3 \square$ & $15(93.7)$ & & \\
\hline ined antibiotic & $15 \square 6.3 \square$ & $262 \square 100.0 \square$ & & \\
\hline \multirow[t]{5}{*}{ n of postoperative antibiotic(\%) } & & & $\chi^{2}=19.359$ & 00.001 \\
\hline & $3 \square 9.1 \square$ & $30 \square 90.9 \square$ & & \\
\hline & $15 \square 5.1 \square$ & $278 \square 94.9 \square$ & & \\
\hline & $23 \square 6.0 \square$ & $360 \square 94.0 \square$ & & \\
\hline & $28 \square 17.2 \square$ & 135ロ82.8ロ & & \\
\hline (IQR) & $\begin{array}{c}7.0 \square 4.0- \\
9.0 \square\end{array}$ & $5.0 \square 3.0-7.0 \square$ & $\mathrm{U}=41725$ & $\square 0.001$ \\
\hline
\end{tabular}


Jle5 Results of Multivariate logistic regression analysis

\begin{tabular}{lccccc}
\hline iables & B & OR & $95 \%$ CI & Statistic & P value \\
\hline nder $\square$ male $\square$ & 0.790 & 2.204 & $1.178 \sim 8.985$ & 6.576 & 0.010 \\
od glucose $>124 \mathrm{mg} / \mathrm{dL} \square$ & 1.202 & 3.328 & $1.888 \sim 5.867$ & 17.286 & $<0.001$ \\
\hline orectal surgery & 1.950 & 7.027 & $3.577 \sim 13.805$ & 32.031 & $<0.001$ \\
proach(Laparoscopic) & -1.579 & 0.206 & $0.099 \sim 0.430$ & 17.700 & $<0.001$ \\
estinal obstruction & 0.680 & 1.973 & $1.014 \sim 3.838$ & 4.009 & 0.045 \\
:gical duration( $>122 \mathrm{~min})$ & 1.073 & 2.923 & $1.673 \sim 5.106$ & 14.204 & $<0.001$ \\
\hline
\end{tabular}

\section{Figures}

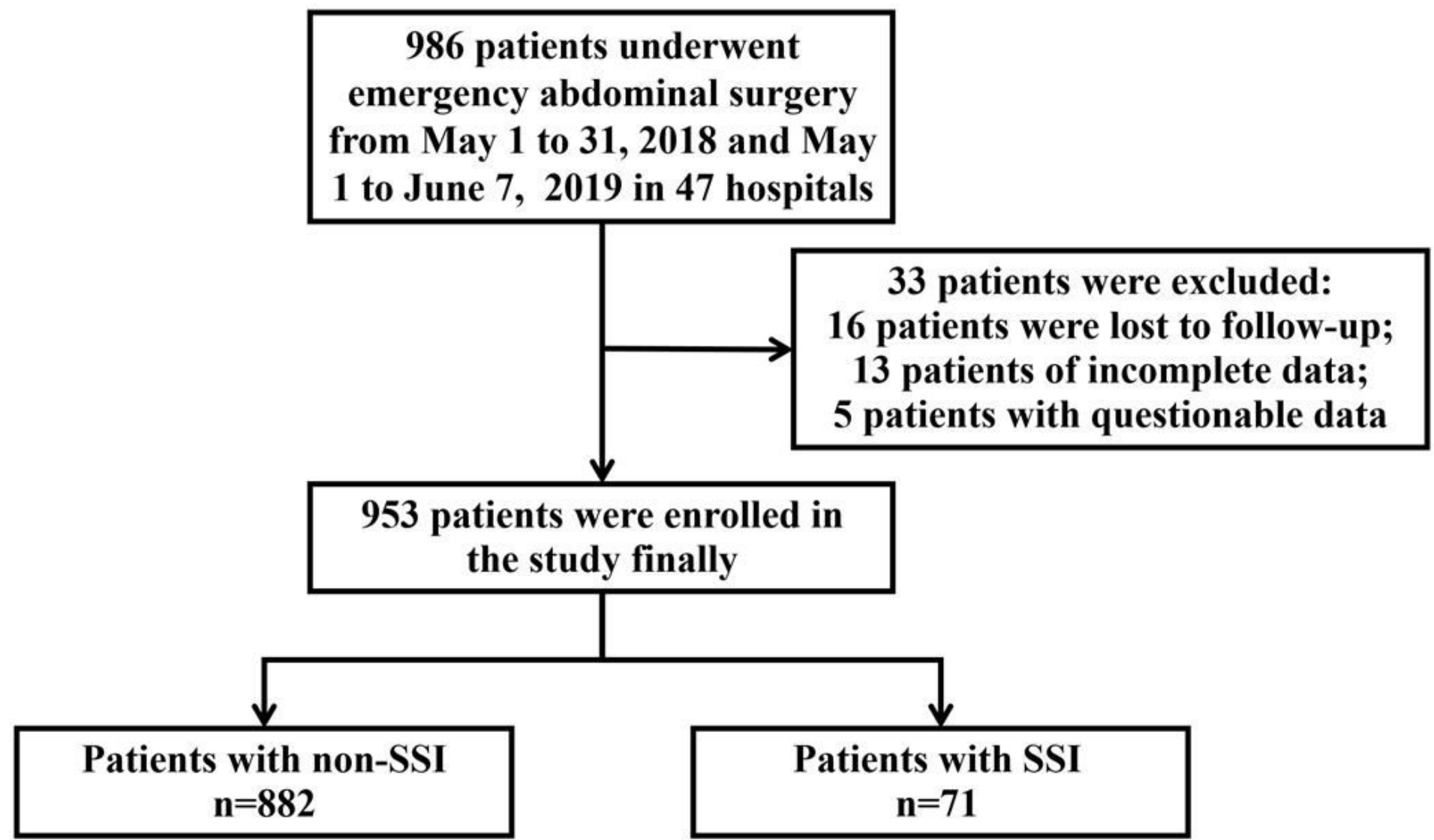

Figure 1

Patient flow chart 


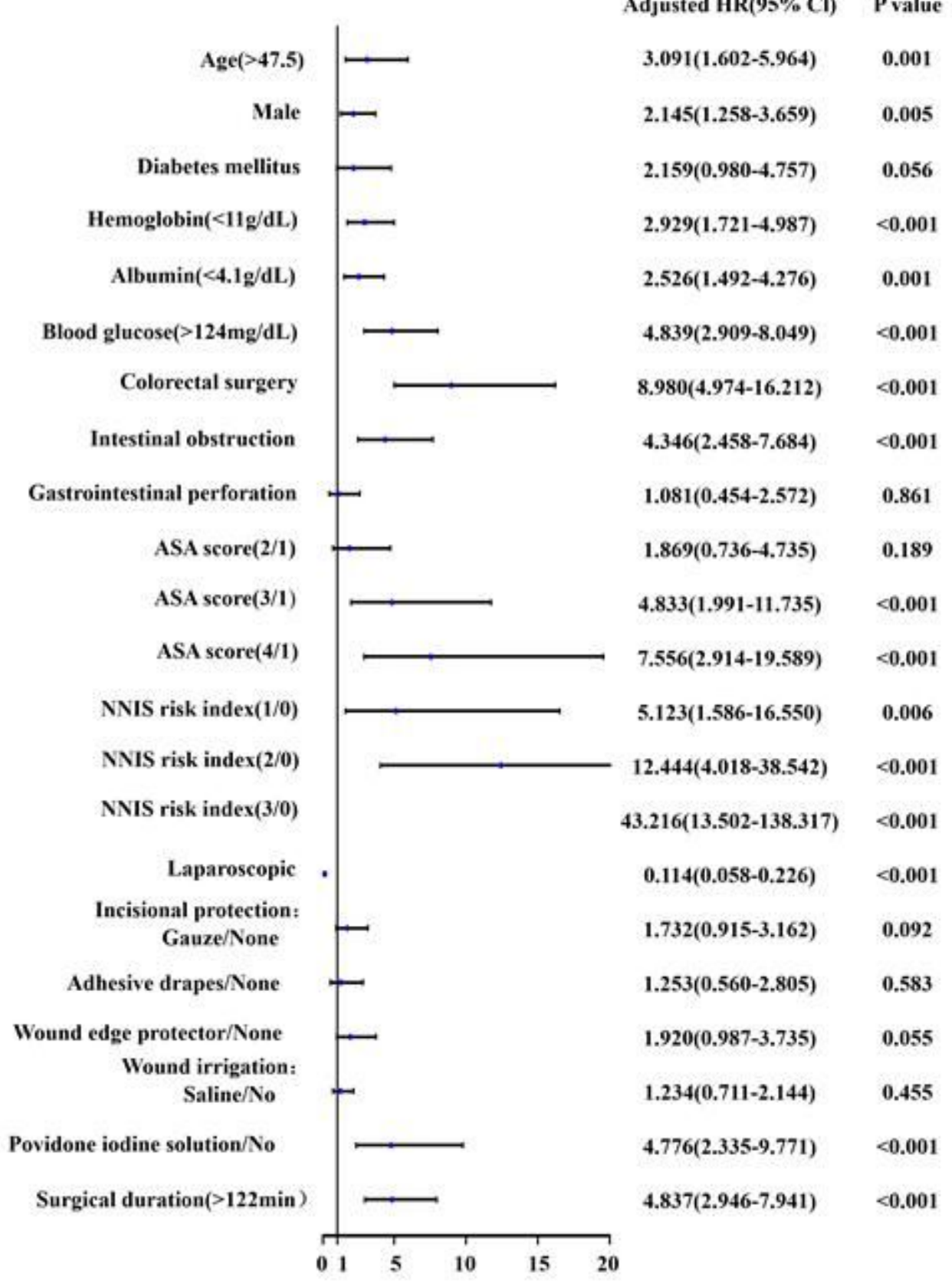

\section{Figure 2}

Results of univariate logistic regression analysis

\section{Supplementary Files}

This is a list of supplementary files associated with this preprint. Click to download.

- supplement1.docx 